\title{
DUAL FREQUENCY RADAR ICE AND SNOW SIGNATURES
}

\author{
By R. D. Ketchum, JR \\ (Polar Oceanography Branch, Oceanography Division, Naval Ocean Research and \\ Development Activity, NSTL Station, Mississippi 39529, U.S.A)
}

\begin{abstract}
Dual frequency (X-band and L-band) synthetic-aperture radar imagery of sea ice is examined to show the differences between the bands and their complementary nature for resolving ambiguities in interpretation. High backscatter at X-band from visibly smooth thin ice is not observed at L-band. One hypothesis is that the high $\mathrm{X}$-band backscatter may be caused by a reflective layer at the snow/ice interface. A second hypothesis is that the high X-band backscatter may be caused by moisture in the snow. A third hypothesis states that the phenomenon may be due to snow flowers. High backscatter at L-band is observed for slush on open water. The return is very weak at X-band, thus allowing distinction of slush by comparing L-band and X-band images. High intensity, but only partial returns from icebergs at L-band have been observed. The hypothesis is that internal iceberg/sea-water reflections are occurring. Some signals are directed away from the antenna, other reinforced signals are returned, producing very bright images. Occasionally, time-delayed signals are returned causing a false image at far range from the iceberg. The conclusion is that L-band is a poor choice for studies of iceberg distribution and size, but a good choice for iceberg detection because of the high reinforced returns from many icebergs and the low return from the adjacent sea ice. The penetration and subsequent signal loss of L-band in glacial ice, when compared to high X-band returns, may be useful to map glacierized land masses.
\end{abstract}

Résumé. Les signatures de la glace et de la neige dans un radar à double fréquence. On examine l'image de la glace de mer donnée par un radar à double fréquence (bandes X et L) et on montre les différences entre les bandes et leur complémentarité pour résoudre les ambiguités dans l'interprétation. Un forte réflexion dans la bande X à partir d'une glace visiblement lisse et mince n'est pas observée dans la bande L. Une hypothèse est que cette forte réflexion à la bande $\mathrm{X}$ provient d'un niveau réfléchissant à l'interface neige glace. Une seconde hypothèse est que ce niveau à forte réflexion dans la bande $\mathrm{X}$ peut provenir de la présence d'humidité dans la neige. Une troisième hypothèse dit que le phénomène peut être attribué aux fleurs de neige. La forte réflectivité dans la bande L est observée pour le "slush" en eau libre. Le retour est trés faible pour la bande X, ce qui permet de caractériser le «slush" par comparaison des images dans les bandes X et L. On a observé des réflexions de forte intensité mais seulement partielles pour les icebergs dans la bande L. L'hypothèse est qu'il y a des réflexions internes iceberg/eau de mer. Certains signaux sont dirigés loin de l'antenne: d'autres signaux sont envoyés renforcés, donnant des images brillantes. Parfois des signaux sont renvoyés avec un temps de retard provoquant une fausse image loin de l'iceberg. La conclusion est que la bande L est mal adaptée à l'étude de la distribution et de la forme des icebergs, mais convient bien pour la détection de la présence des icebergs à cause des réflexions abondantes et renforcées en provenance de beaucoup d'icebergs et de faibles réflexions de la glace de mer voisine. La pénétration et, partant, la perte de la bande L dans la glace de glacier, en comparaison à la forte réflexion dans la bande $\mathrm{X}$ peuvent servir à cartographier les masses glaciaires continentales.

Zusammenfassung. Doppelfrequente Radar-Signaturen von Eis und Schnee. Radar-Bilder von Meereis, gewonnen mit synthetischer Apertur und Doppelfrequenzen im X- und L-Kanal, werden untersucht, um die Unterschiede zwischen den beiden Kanälen und ihren komplementären Charakter bei der Aufklärung von Mehrdeutigkeiten in der Interpretation aufzuzeigen. Die hohe Rückstreuung von sichtlich glattem, dünnem Eis im X-Kanal tritt im L-Kanal nicht auf. Als Hypothese wird ihre Entstehung durch eine reflektierende Schicht an der Grenze zwischen Schnee und Eis angenommen. Eine zweite Hypothese sieht die Ursache dieser Rückstreuung in der Feuchtigkeit des Schnees. Eine dritte Hypothese macht „Schneeblumen” für dieses Phänomen verantwortlich. Hohe Rückstreuung im L-Kanal tritt bei Matsch im offenen Wasser auf. Im X-Kanal ist dort das Signal sehr schwach, so dass Matsch durch Vergleich der Bilder im L-und X-Kanal erkannt werden kann. Im L-Kanal liefern Eisberge Signale hoher, aber nur partieller Intensität: dies wird damit erklärt. dass innere Reflexionen zwischen Eisberg und Meerwasser vorhanden sind. Einige Signale werden von der Antenne weg gerichtet: andere verstärkte Signale werden zurückgeworfen, wodurch sehr helle Bilder entstehen. Gelegentlich werden zeitverzögerte Signale zurückgeworfen, so dass ein falsches Bild weit entfernt vom Eisberg entsteht. Die Folgerung ist. dass der L-Kanal für das Studium der Verteilung und Grösse von Eisbergen wenig, jedoch zur Entdeckung von Eisbergen wegen der 
verstärkten Echos von vielen Eisbergen und dem schwachen Echo vom umgebenden Meereis gut geeignet ist. Die Durchdringungsfähigkeit und die daraus resultierende Schwächung des L-Kanals in Süsswassereis kann bcim Vergleich zu den starken Echos im X-Kanal zur Kartierung vereister Landmassen nützlich sein.

\section{INTRODUCTION}

The intrinsic value of synthetic aperture radar (SAR) for mapping sea ice has been recognized for years. More recently, the operational applications of radar systems in sea-ice related work have increased significantly due to increased interest in oil exploration in icecovered seas. Additionally, there is an on-going desire to apply SAR systems to sea-ice research programs to study distribution and dynamics of ice features, with an eye on future satellite systems. As a result, SAR experimental activities and sea-ice investigators have increased in number. This effort has led to the realization, more so than before, that SAR sea-ice imagery interpretation may, in some areas, be extremely complex. The purpose of this paper is to point out that radar sea-ice imagery interpretation techniques must be keyed to geographical areas, seasonal changes within an area, and, of course, the radar parameters used. In the last case, frequency and antenna depression angle seem to be the most important parameters.

Over the years, much effort has been spent to relate stages of ice development, or categorical ice thicknesses, to radar backscatter. Surface roughness has been the main criterion for this determination. The premise is that new ice types and later first-season ice forms have experienced less deformation and erosion than older forms, thus have smoother surfaces, and produce less radar backscatter. For years, sea-ice experiments using radar scatterometers and radar imaging systems showed that, in general, this was true. Most of these experiments were conducted in the higher northern latitudes during the colder winter months and a great deal of documentation of actual surface conditions was not available. Plans for all-weather, day-and-night operational radar systems for identification of ice thickness distribution, as well as other ice/water features, have been based on the premise that accurate and reliable ice classifications could be made using radar backscatter information. In more recent years, with an increase in coincident correlative airborne and surface data, it has become apparent that this may not be true, at least not for all ice regimes.

Misinterpretations of sea-ice radar imagery can easily occur if we rely primarily on backscatter data. Some examples, with possible explanations, are given for a number of the unusual returns which vary from the classical or the anticipated. Substantial evidence does not exist to support the explanations, but it is hoped that drawing attention to these non-classical returns will prompt other investigators to develop explanations which will improve our understanding of the interactions of radar signals with the environment. This will benefit future interpretation and enable better recommendations for system parameters to be used in future work. Also, radar imagery interpretation analysis, now going on, may avoid interpretation "pitfalls" if there is more awareness of the ambiguous radar returns.

The SAR imagery used was taken during the ice experiment of the Canadian Surveillance Satellite (Sursat) Project in the Spring of 1979. A steep antenna depression angle was employed providing surface coverage from nadir outward to $53^{\circ}$. The imagery obtained near nadir typically appears to be of poor quality due to poor range resolution at extremely steep depression angles. The SAR System simultaneously provided four channels of data; X-band at $3 \mathrm{~cm}$ and Lband at $25 \mathrm{~cm}$, each with like $(\mathrm{HH})$ and cross (HV) polarized channels (INTERA Environmental Consultants, Ltd., 1978). This SAR imagery is not calibrated, thus all inferences to radar 
backscatter are based on gray-tone differences, which may change from image to image. In addition, the dynamic range of the imagery has been adversely affected by the several generations of reproduction required to reach the final printable product. Consequently, interpretation in this report may not be depicted as clearly as they were on the imagery used in analysis.

Simultaneous photography was taken with an RC-8 aerial camera by the Naval Ocean Research and Development Activity (NORDA) during joint flights of a Navy P-3A aircraft with the Canadian SAR equipped Convair 580.

\section{SNOW DYNAMICS}

A most common and widespread ambiguity which can lead to much confusion and serious errors in interpretation of $\mathrm{X}$-band sea-ice imagery appears to be caused by the snow dynamics and the effects of snow cover on the ice. Low radar backscatter is normally anticipated from smooth thin ice (nilas, young, thin first-year ice), but recent experiments have shown that unusually high, homogeneous gray-tone returns from apparently undeformed thin-ice surfaces are not uncommon. This observation has been especially true for thin-ice areas in the marginal ice zone.

Ketchum (1977) hypothesized that with various balances of ice thickness, snow depth, air temperature, and time, a radar reflective layer of recrystallized snow and ice may develop at the snow-ice interface. Heat conducted through the underlying ice is trapped at the snow-ice interface and causes melting. With subsequent decreases in temperatures, a recrystallization of snow and ice occurs at the snow-ice boundary increasing porosity. This newly developed layer is a volume which scatters X-band radar. The rate and degree of reflective interface development would be a function of all the variables, but is probably most dependent on ice thickness (i.e., thinner ice will transmit heat to the surface at a greater rate, and will be more saline).

A second hypothesis, closely related to the first, states that a residual material developed by (perhaps repeated) melting and refreezing of snow cover on thin ice may also cause development of a thin layer which scatters X-band radar (Ketchum and Farmer, 1980). This process and the resulting medium would be very similar to those described above. However, in this case, a thinice area might not appear snow-covered as it would with the snow-ice interface phenomenon. Identification of this surface medium, as with the snow-ice interface layer, would be very difficult on aerial photography. The medium could possibly be inferred, for example, if subsequent surface flooding destroyed the backscattering layer. The radar backscatter would be reduced and a changed appearance on the photography would also occur.

A third hypothesis states that a high X-band return could be caused by an abundance of snow flowers, a common occurrence on thin ice. Ice flowers are delicate tufts of frost of rime which apparently have salt crystals acting as nuclei.

During the experiment in south Baffin Bay, air temperatures were just one or two degrees below freezing. Personnel who made helicopter landings on the ice reported a very wet snow cover. Ketchum and Farmer (1980) related high homogeneous X-band radar returns to high snow-moisture content. Stiles and Ulaby (1980), from surface-based studies, also have reported an increased radar backscatter coefficient from moist snow with an accompanying decrease in backscatter from the underlying terrain.

The conditions mentioned above are believed to be responsible for high X-band radar returns, and these returns are very often from smooth areas of thin ice; thus they produce a 
major and serious ambiguity in sea-ice interpretation (i.e. high X-band returns are usually associated with visible surface roughness and with older ice types). This ambiguity can usually be satisfactorily resolved if simultaneous L-band radar imagery exists. The L-band signal is not appreciably scattered by these reflective layers, giving only a weak return signal, and a proper interpretation can be made. Ice and weather conditions in the marginal ice zones are favorable for the development of the X-band radar reflective layers discussed above. Simultaneous use of $\mathrm{L}$-band and $\mathrm{X}$-band radars will be helpful to produce more precise interpretations of sea-ice data in the marginal ice zones.

The differences in the $\mathrm{X}$ - and L-band image gray tones or radar backscatter shown in Figure 1 are attributed to the effects of snow. The greatest radar backscatter differences between the two radar bands are shown by the apparent smooth areas of thin ice with snow cover, some of which have been labeled "A". Some of the highest X-band radar returns come from these areas. Evidence of recent snowfall is apparent on the thinnest ice forms shown here. Some of the rafted areas of thin ice display an obvious snow cover, but this condition could not persist long with thin ice types and air temperatures near $0^{\circ} \mathrm{C}$ as they were during this experiment. The snow has deteriorated on the thinner unrafted areas. The X-band imagery shows significant and nonuniform returns from these areas. It is believed that the X-band radar returns are from surfaces affected by physical changes related to an earlier snow cover and/or the present wet snow cover. L-band imagery is not noticeably affected by these ice/snow features.

Areas of consolidated and unconsolidated fragments in Figure 1 are providing a good return to both radars. Surface roughness is probably the principal reason for the high L-band radar

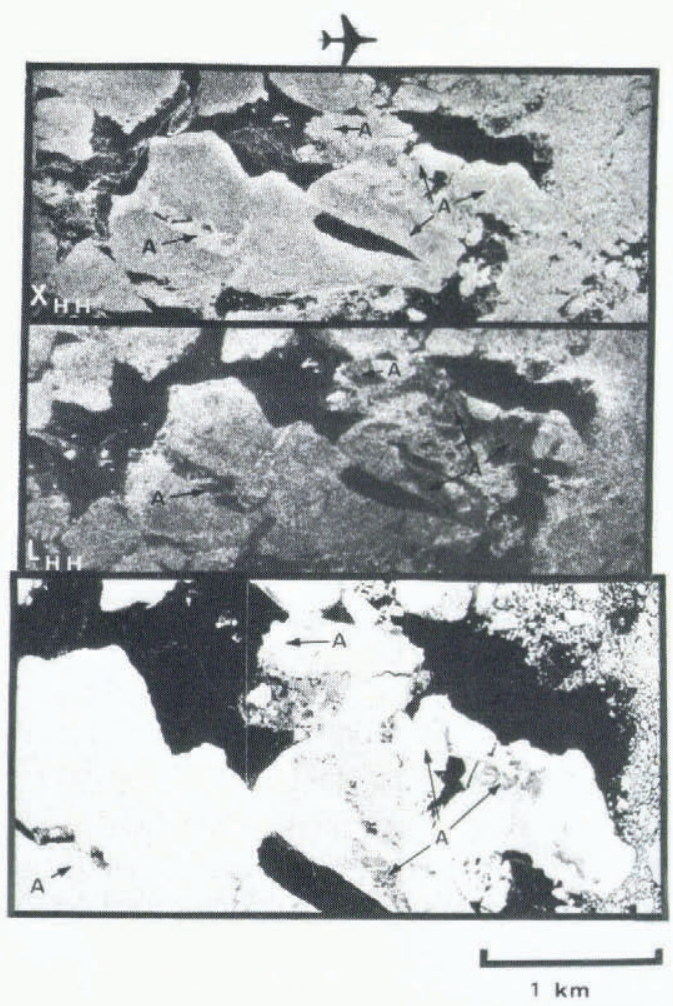

Fig. I. Strong X-band backscatter and weak L-band backscatter are shown from smooth, thin snowcovered ice in Baffin Bay, April 1979. 
return, but surface geometry and the effects of snow may both be responsible for the good Xband radar return. The areas of consolidated ice are not discriminated from the closely-packed unconsolidated fragments by either radar.

\section{SLuSH}

Some areas in Baffin Bay, which initially appeared to be open water on the photography, produced a high, homogeneous radar return on the L-band imagery, but very weak returns on the X-band imagery. These areas on the L-band imagery could not be discriminated from the surrounding high-return areas of consolidated and closely packed first-year ice and young ice types. The distinction, however, could be made with the X-band imagery. Close examination of the photographic negatives has shown that these "ice-free" areas are slush covered. This condition was observed over the central portion of a $100 \mathrm{~km}$ long strip of radar imagery. Openwater polynyas toward the ends of the radar strip provided very low returns at both frequencies. Available coincident photography did not reveal any slush on these polynyas. Atmospheric conditions over the experimental area before and during the flights were favorable for snow showers. It is suggested that local snow showers over the central portion of this section caused the formation of slush.

Some examples of this condition are illustrated with $\mathrm{X}$ - and L-band radar imagery and coincident photography in Figure 2. The photography shows large areas of open water. These

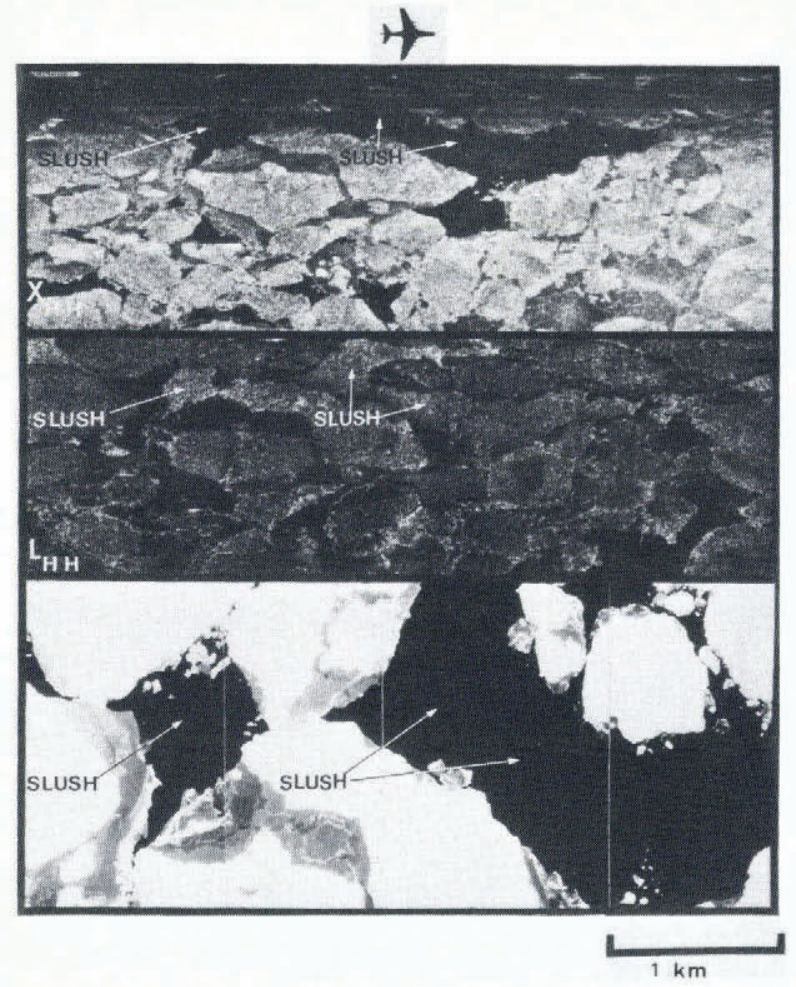

Fig. 2. Strong $L$-band backscatter and weak $X$ band backscatter are shown from slushcovered water in Baffin Bay, April 1979. 
same open-water areas are well delineated on the X-band imagery as weak return areas. However, many of these same areas are providing good radar returns on the L-band imagery and cannot be distinguished from the surrounding ice images. This condition is believed due to a layer of slush on the waster. Further evidence of this phenomenon is seen in the X-and L-band radar imagery in Figure 3 where, interestingly, opposite radar returns from the nilas and slushcovered open-water areas are shown on the X-and L-band radar imagery. Small fragments of ice have moved through the slush on the left end of the image producing ice-free wakes which appear as areas with very low return on the L-band imagery.

The boundary between the slush layer, which is essentially a fresh-water ice formation, and the underlying sea-water would be an irregular boundary with high dielectric contrast and with sufficient reflectivity to produce both $\mathrm{X}$ - and L-band backscattering. The high water content of the slush makes it a very lossy material. It is possible that the slush layer was thin enough to permit a strong return of the L-band signals from the slush-water boundary. Only very weak returns are observed on the $\mathrm{X}$-band imagery, because this shorter wavelength is more rapidly attenuated in the slush layer. The ambiguity of the L-band returns can be resolved by correlating the L-band imagery with the simultaneous X-band imagery. Again we see high radar returns which could be used erroneously to classify ice conditions. High L-band returns are generally associated with a visibly rough surface geometry (i.e. hummocks, ridges, brash, blocks) although there is increasing evidence that sea-ice subsurface returns may play an important role when using L-band radar (Ketchum, 1978; Ketchum and Farmer, 1980).

\section{ICEBERGS}

The practicality of using L-band radar imagery to make iceberg counts or to study iceberg distribution and size has become very questionable since the collection of the April 1979 SAR data in Baffin Bay. Many icebergs were not as completely "painted" on the L-band imagery as they were on the X-band imagery. The L-band imagery suggests that the L-band signal is penetrating the iceberg and that multiple internal reflections within the iceberg are occurring. The

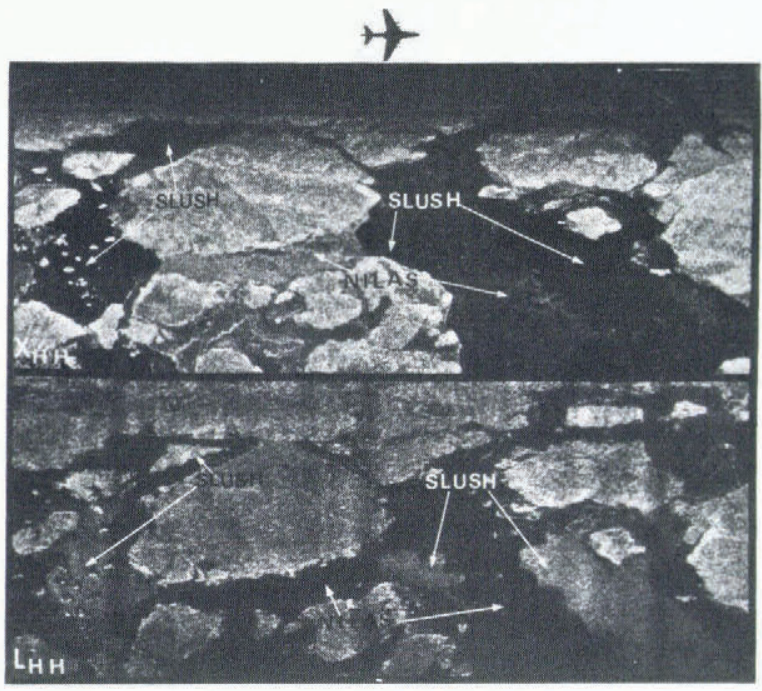

Fig. 3. L-band radar reccives strong returns from slush-covered water and weak returns from nilas. $X$-band radar receives weak returns from slush and strong returns from nilas. 
momentarily "captured" signals may either exit the iceberg in a direction away from the radar antenna, or back to the antenna. In either case a signal void appears at the position of the iceberg due to the time delay and/or lack of signal return. When the signal is directed to the antenna after multiple reflections within the iceberg, false images may appear on the far-range side of the iceberg.

Examples of these phenomena are shown in Figure 4. Several icebergs are shown on X-and L-band imagery along with some coincident photography. The iceberg at A appears very much the same on both channels. The iceberg at B, on X-band imagery, has a triangular radar shadow. The size and shape of the iceberg, as can be seen on the photograph, corresponds with this. A similarly shaped, but larger low-return area, appears on the L-band imagery on the far-range side of the iceberg at B. Beyond the "shadow" are two bright return areas. These are believed to be images of time-delayed signals which were momentarily "captured" within the iceberg. The "void" area probably represents the time delay. There is no evidence on the photography of any ice terrain feature which could account for the two bright images. The iceberg at C, very apparent on X-band imagery, gives very little return on L-band imagery. The iceberg is a lowreturn area with the exception of a weak return from the near range edge and a small bright return within the outline of the iceberg. Most of the signal from this iceberg has been lost. The iceberg at D seems to be well imaged on the X-band image. On the L-band image five small distinct bright images represent returns from this iceberg. The remainder of the iceberg area shows only weak returns. The large iceberg at $\mathrm{E}$ is well portrayed on the $\mathrm{X}$-band image. On the $\mathrm{L}$-band image a high signal return from the near-range edge is depicted. A weaker signal return is shown from the far-range end of the iceberg. The majority of the iceberg is not displayed,

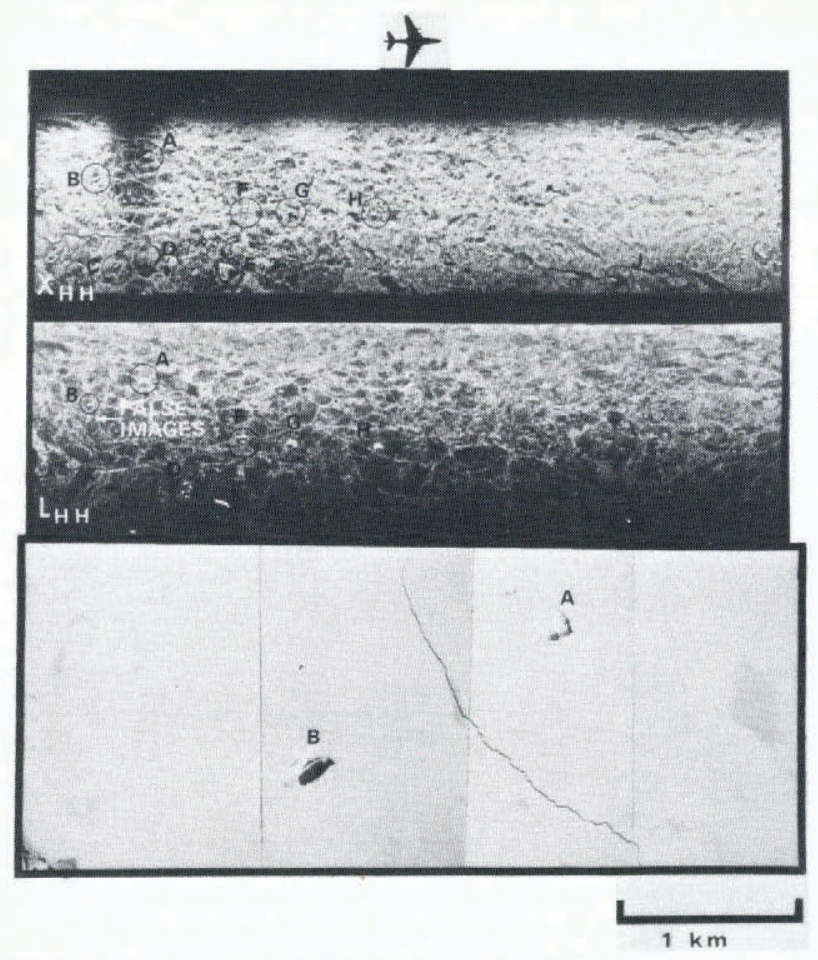

Fig. 4. L-band radar signals may experience multiple internal reflections which can lead to a signal loss. If these time-delayed signals are directed back to the radar antenna, they appear as false images. 
indicating low backscatter to the antenna. A similar condition is shown by the iceberg at F. It appears to be well painted on the X-band image, but returns on the L-band image are apparent only from the near-range edge and from a small area within the iceberg. The icebergs at $\mathrm{G}$ and $\mathrm{H}$ are portrayed on both channels in a similar fashion.

The high signal returns from the icebergs seen on the L-band imagery are probably reinforced returns which have resulted from reflections within the iceberg. The areas within the icebergs void of signal returns represent time delays and/or areas where the signal after internal reflections left the iceberg in a direction away from the antenna. It can be seen here that background returns from the surrounding sea ice are often low on the L-band imagery, while the signal returns associated with the icebergs often seem to saturate the system indicating signal reinforcement. A good example of this is shown by the iceberg at $\mathrm{J}$ in Figure 4.

The reflections within the iceberg could be related to structural features (i.e. cracks, layers of water or sediment) but it is believed most probable that the reflections are at the iceberg-seawater interface, an interface of high dielectric contrast with may be smooth, therefore leading to specular reflections of the incident signals. The sides of the iceberg may act somewhat like a corner reflector in that the signals experience multiple internal reflections before leaving the iceberg. Signal exit would most likely occur at an iceberg-air interface, where the dielectric contrast is low. If the signal reaches the radar antenna, the false images are recorded and indicate the duration of the time delay. The apparent strength of some of the returned L-band signals indicates signal reinforcement. In many instances where background sea-ice signal returns are subdued at far range, those signals from the icebergs seem to have saturated the system. Multiple internal reflections could lead to signal reinforcement. It could also bring about a destructive interference of signals causing data nulls. Once the likelihood of multiple internal reflections is accepted, one can also accept the possibility of both constructive and destructive interference of signals. This could lead both to the apparent signal saturation and signal voids observed here. In any event, it seems clear that L-band radar signals are interacting in unpredictable ways with icebergs, unpredictable because of the wide variations of size, shapes, and physical properties which may be encountered with icebergs. Because of this, the L-band radar is not a good candidate for iceberg counts or studies of iceberg distribution and size estimates. On the other hand, as can be seen in Figure 4, there are times when an iceberg is better detected with L-band than with X-band radar. There are two reasons for this. Generally, there is less sea-ice background clutter to obscure the iceberg target, and the signal reinforcement often associated with the iceberg backscattering phenomena enhances the iceberg detectability. Numerous icebergs are shown on X-and L-band imagery in Figure 5. These icebergs, which are located in Melville Bay, were calved from local glaciers. This area is a major source of icebergs for Baffin Bay. Many differences can be noted in the appearance of some of these icebergs on the X-and L-band imagery. Many false images are also present on the L-band imagery. Of interest here is the difference in radar backscatter of the two frequencies from the glacierized land areas. X-band radar usually gives a high return from both the land mass and the glacierized areas, but L-band appears to show the glaciers as areas of low radar return. Similar comparisons were seen on coincident $\mathrm{X}$ - and L-band imagery taken over glacierized areas of Baffin Island during this experiment. Apparently, the L-band radar energy is penetrating the glacial ice, just as has been hypothesized for icebergs, and at some subsurface interface the energy is either being absorbed or reflected away from the radar antenna. Possibly the energy is being absorbed during its travel through the glacier ice. The resulting imagery portrays only weak returns. The X-band radar energy is returned from the glacier ice and the imagery shows high returns. In any case, 


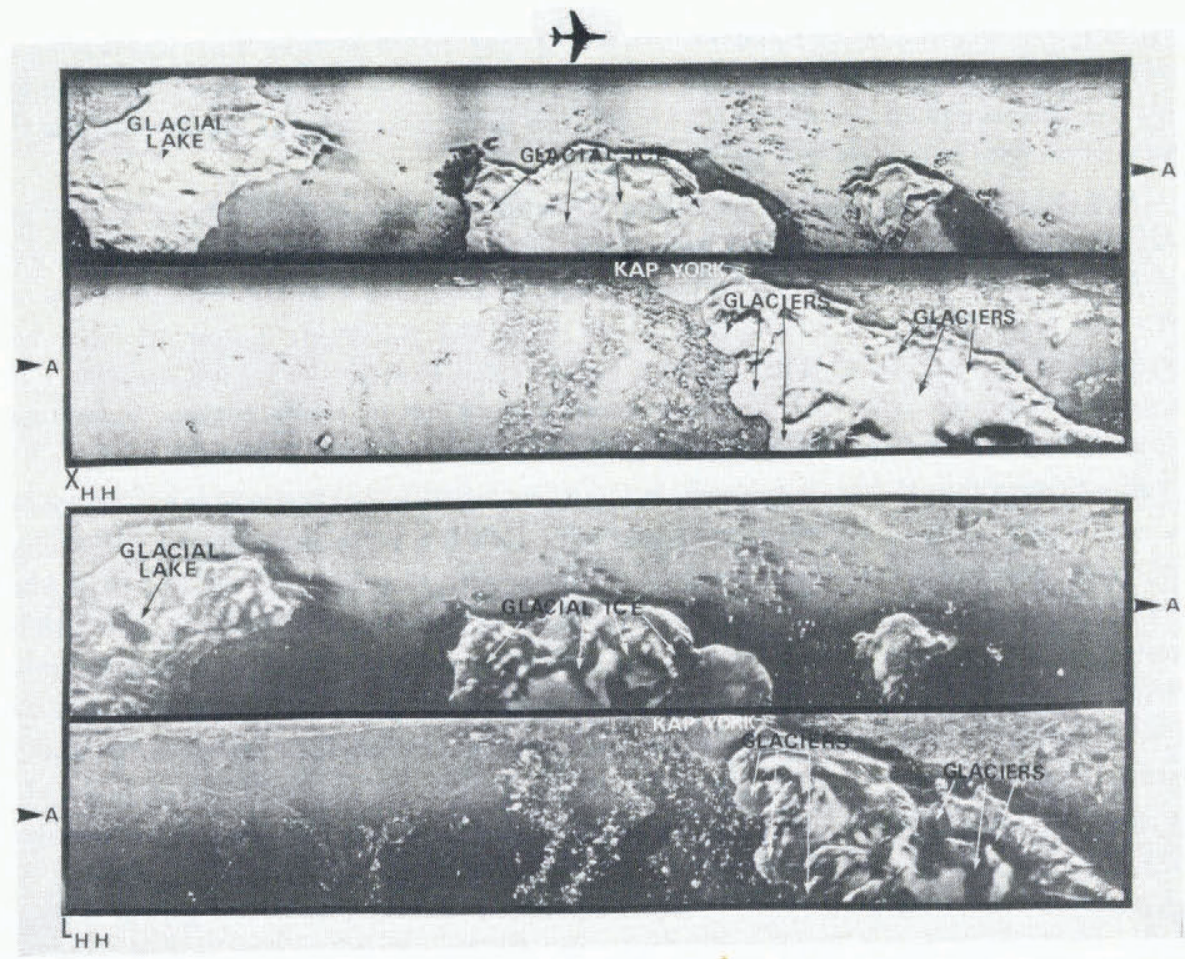

Fig. 5. Glacierized land masses produce strong $X$-bandscatter and weak $L$-band backscatter. Comparison of the two channels enables delineation of the glacier ice.

indications are that when using the two radars simultaneously, a comparison of the resultant imagery may allow delineation of the distribution of glacierized areas.

\section{CONCLUDING REMARKS}

Observations of high X-band radar backscatter from apparently smooth, snow-covered, or previously snow-covered, areas of thin ice has led to the conclusion that snow has a profound effect on the development of a radar backscattering layer. The exact nature of this backscattering layer is not known, but it is believed to develop as a result of melting and refreezing of the snow, and of the surface ice layer immediately beneath the snow. A resultant increase in the porosity of this layer could account for higher X-band backscatter. The strength of the backscattered signal would be related to the degree of development, or porosity increase, in the backscattering layer. Large variations in X-band backscatter, if dependent on this phenomenon, could occur, but would not necessarily be related to ice thickness. However, the phenomenon is more prominent on thin ice types because their warmer ice-surface temperatures contribute to the melting process. There is a greater incidence of thin ice types, snow, and large temperature fluctuations in the marginal ice zones of the Arctic. These factors all contribute to the recrystallization process of the ice and snow. Therefore, high X-band radar backscatter from areas of smooth ice should be anticipated in the marginal ice zones. 
The radar backscatter related to slush forms on water has not been observed before by the author. In the present data, only weak radar returns from slush covered areas were observed on the X-band imagery, but the high L-band radar return signals were sufficiently strong to preclude discrimination of the slush-covered areas from the surrounding high backscattering ice breccias. Because the condition is believed to be related to heavy snow precipitation, it would be most common in marginal ice zones.

The dual-frequency imagery of icebergs and land-glacier ice has revealed some unsuspected but interesting results which need to be investigated in greater depth. L-band radar imagery does not always provide good delineation of icebergs. The concept of L-band radar signals undergoing multiple internal reflections in icebergs, a phenomenon which results in time-delayed signal returns or no signal returns, seems plausible. Low-return areas in the iceberg images and false images associated with some icebergs are not uncommon. However, the L-band returns from icebergs are often very strong, even when the returns from background ice surfaces which normally show high backscatter are somewhat suppressed at far range. This suggests signal reinforcement. This phenomenon, combined with the reduced background clutter associated with L-band radar, often enables icebergs to be more readily detected. On the other hand, lack of signal return and/or more than one distinct signal from a single iceberg reduces the reliability of L-band radar for application to iceberg distribution studies and size estimates.

Low L-band radar returns from glacier ice as opposed to high X-band returns has led to the speculation that the comparative analysis of coincident X-and L-band imagery may allow mapping of the distribution of glacierized land masses.

Results of recent studies of ice are beginning to show that radar backscattering characteristics of sea ice can be very ambiguous and also ephemeral. This is particularly true with the higher-frequency radar systems, such as X-band in the marginal ice zones. Shape and size analysis and feature association play very important roles in radar sea-ice imagery interpretation. Computer-aided quantitative techniques to classify and describe ice conditions should include these criteria as well as gray tones and textures.

\section{MS. received 18 June 1982 and in revised form 8 September 1982}

\section{REFERENCES}

INTERA Environmental Consultants, Ltd. 1978. The SAR-580 production system. INTERA Report ASP-78-8.

Ketchum, R. D., jr. 1977. An evaluation of side looking radar imagery of sea ice features and conditions in the Lincoln Sea, Nares Strait, and Baffin Bay $(U)$. NSTL Station, Mississippi, Naval Ocean Research and Development Activity. (NORDA Technical Note 7.)

Ketchum, R. D., jr. 1978. An evaluation of ERIM X-L band airborne synthetic aperture radar imagery of sea ice. NSTL Station, Mississippi, Naval Ocean Research and Development Activity. (NORDA Technical Note 28.)

Ketchum, R. D., jr, and Farmer, L. D. 1980. Eastern Arctic Sursat SAR ice experiment: radar signatures of sea ice features. NSTL Station, Mississippi, Naval Ocean Research and Development Activity. (NORDA Technical Note 68.)

Stiles, W. H., and Ulaby, F. T. 1980. The active and passive microwave response to snow parameters. 1. Wetness. Journal of Geophysical Research, Vol. 85, No. C2, p. 1037-44. 